\section{Myths of gender}

\section{Adrienne Zihlman}

Female Choices: Sexual Behaviour of Female Primates. By Meredith F. Small. Cornell University Press: 1993. Pp. 245. \$26.95.

The Lemurs' Legacy: Evolution of Power, Sex, and Love. By Robert Jay Russell. Tarcher/Putnam: 1993. Pp. 274. \$21.95.

WHAT makes women women? What makes men men? Although navigating similar waters - sexual and mating strategies - supposedly with the same compass - evolution - the authors of these two books take different tacks to answer these questions, and arrive at different finishing lines.

Meredith F. Small focuses on sexual activity and mate choice because reproduction is "the nitty-gritty of evolution". She compares human and nonhuman primate females in order to trace the evolution of human female behaviour.

Darwin first discussed mate choice in The Descent of Man and Selection in Relation to Sex (1871). He asked why females and males look and behave differently and proposed two channels for passing on sex-specific features: competition among males and female choice. Viewing females as relatively passive and less eager sexual partners, Darwin thought competition between males to be the more powerful selective force. According to Small, it wasn't until the feminist revolution in animal behaviour that interest in female choice hit its stride. Robert Trivers gave mate choice a boost by proposing in 1972 that the sex investing the most energy in rearing offspring has the power of selection.

Emphasizing primate behavioural flexibility and drawing on long-term studies of free-ranging monkeys and apes, Small depicts females as anything but passive. On the contrary, they are sexually assertive and eager for novelty and variety. Theory, of course, dictates that females should choose the male with the best genes (but how can she know?) or the best parent (how can she judge?). In reality, female primates (including those of our own species) are not always so discriminating. In monkey societies, a female sometimes chooses lower-ranking males even though higher-ranking males harass her. Small suggests that the widespread phenomenon of male transfer between social groups occurs because females prefer to mate with the new guy on the block.

Female homosexual behaviour is "just part of a larger portrait of a highly sexual, even promiscuous, and not particularly choosy animal". Females experience orgasm, and human females are no different from their nonhuman cousins, for whom natural selection provides sexual pleasure as an incentive to mate and reproduce. Small thus emphasizes an equal-opportunity approach to female and male sexuality. Some cultural practices may have originated because of the perception of women as wild sexual beings needing to be brought under control. The 'double standard' then reflects more the power of males to control female sexuality than biological differences in sexual desire.

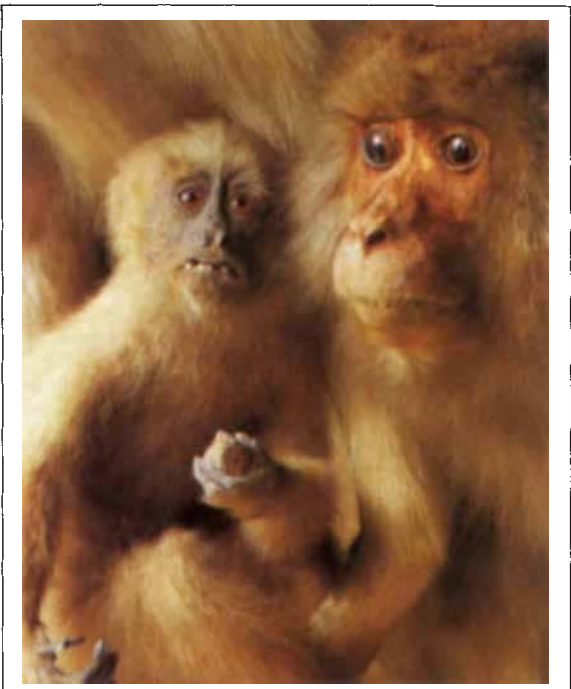

Stuffed macaques acquired by Philip Franz von Siebold during his travels in Japan, 1823-29. From Finders, Keepers by Stephen Jay Gould and Rosamond Wolff Purcell (see box on page 586).

In contrast to Small's carefully defined agenda, Robert Jay Russell attempts to trace the roots of human power, sex and love. Like Small, he begins with sexual reproduction but goes on to argue that male testosterone is the basis for differences in female and male behaviour and motivation. Darwin's Expression of the Emotions in Man and Animals (1872), according to Russell, laid the foundation for the new field of evolutionary psychology.

Lemur society, a hypothetical first stage in the evolution of human behaviour, is characterized by long-term ties between mother and daughters. Juvenile males join bachelor groups, interacting with females during an annual month-long breeding season. Lemur females prefer to mate with males that are strong and confident and high-ranking, but not too aggressive. This combination of desirable male qualities is uncommon, Russell explains, because the same hormones that prepare males for mating also trigger aggression. Forced insemination, or rape, is therefore "an integral part of many primate mating systems from lemurs to humans". The lemur legacy is thus a balancing act between nurturing, romance and aggression.

According to Russell, female dominance in lemur social life ended abruptly 24 million years ago when the African lemurs gave rise to the dryopithecine apes. Testosterone-driven, dangerously aggressive males pursued sexual activity with females now receptive every month.

To release this potentially harmful male aggression, Russell argues, ape ancestors more than 20 million years ago began to engage in hunting and warfare. Females became submissive to males, and the consort bond was cemented by an exchange of sex for protection. Russell maintains that prostitution began more than 20 million years ago. The ape legacy further separates the reproductive strategies of men and women because "females seek stable families; males seek novel females. Females seek goods and services (such as protection) in exchange for sex. Males seek sex."

These, of course, are issues of interest in human affairs today. The chief weakness of Russell's argument is time. It is a giant leap for the lemur legacy to affect human behaviour in such detail after 30 to 40 million years of intervening monkey and ape evolution. His evolutionary timescale is outdated. He states, for instance, that gorillas and orangutans have remained unchanged for the past 20 million years, when current evidence indicates that gorillas probably emerged only about 7 million years ago. He attributes remarkably specific behaviour to the dryopithecine apes, although palaeontologists have not yet fully sorted out how many species there were or the details of their locomotion and diet.

The strength of Small's book is that she supports her thesis with real instances from the lives of real monkeys and apes. She shows that in sexual activity and mate choice, females and males may not be as different as has been commonly supposed. Russell, on the other hand, constructs a multi-million-year divergent course for male-female behaviour by imaginary ancestors. The authors disagree widely both about the nature of primate sexuality and about the significant differences between male and female human and nonhuman primates. In evolutionary reconstructions as in everyday life, it remains difficult indeed to find neutral observers of the battle of the sexes.

Adrienne Zihlman is in Clark Kerr Hall, University of California, Santa Cruz, California 95064, USA. 